20. Hultberg. B.: Properties of $\alpha$-mannosidase in mannosidosis. Scand. J. Clin. Lab. Invest., 26: 155 (1970).

21. Hultberg, B., and Masson, P. K.: Activation of residual acidic $\alpha$-mannosidase activity in mannosidosis tissues by metal ions. Biochem. Biophys. Res. Commun., 67: 1473 (1975).

22. Ikonne, J. U., and Desnick, R. J.: Mannosidosis: Characterization of the enzymatic defect. (In preparation.)

23. Ikonne, J. U., Rattazzi, M. C., and Desnick, R. J.. Characterization of hex $S$, the major residual $\beta$-hexosaminidase activity in type $O G_{M_{2}}$ gangliosidosis (Sandhoff-Jatzkowitz disease). Amer. J. Hum. Genet., 27: 639 (1975).

24. Kjellman, B., Gamstorp, I., Brun, A., Ockerman, P. A., and Palmgren, B.: Mannosidosis: A clinical and histopathologic study. J. Pediat., 75: 366 (1969).

25. Leroy, J. G., Ho, M. W., MacBrinn, M. C., Zielke, K., Jacob, J., and O'Brien, J. S.: I-cell disease: Biochemical studies. Pediat. Res., 6: 752 (1972).

26. Loeb, H.: Personal communication.

27. Loeb, H., Tondeur, M., Toppet, M., and Cremer, N.: Clinical, biochemical and ultrastructural studies of an atypical form of mucopolysaccharidosis. Acta Paediat. Scand., 58: 220 (1969).

28. Lowry, O. H., Rosebrough, N. J., Farr. A. L., and Randall, R. J.: Protein measurement with the Folin phenol reagent. J. Biol. Chem., 193: 265 (1951).

29. Masson, P. K., and Lundblad, A.: Mannosidosis: Detection of the disease and of heterozygotes using serum and leucocytes. Biochem. Biophys. Res. Commun., 56: 296 (1974).

30. Mowat, A. G., and Baum, J.: Chemotaxis of polymorphonuclear leukocytes from patients with rheumatoid arthritis. J. Clin. Invest., 50: 2541 (1971).

31. Norden, N., Lundblad, A.. Svensson, S., Öckerman, P. A., and Autio, S.: A mannose-containing trisaccharide isolated from urines of three patients with mannosidosis. J. Biol Chem., 17: 6210 (1973).

32. Norden, N. E., Öckerman, P. A., and Szabo, L.: Urinary mannose in mannosidosis. J. Pediat., 82: 686 (1973).

33. Öckerman, P. A.: A generalized storage disorder resembling Hurler's syndrome. Lancet, ii: 239 (1967).

34. Öckerman, P. A.: Mannosidosis: Isolation of oligosaccharide storage material from brain. J. Pediat. 75: 360 (1969).

35. Park, B. H., Fikrig, S. M., and Smithwick, E. M.: Infections and nitroblue tetrazolium reduction by neutrophils. Lancet, ii: 532 (1968).

36. Phillips, N. C., Robinson, D., and Winchester, B. G.: Mannosidosis in Angus cattle: The enzymic defect. Biochem. J., 137: 363 (1974).

37. Phillips, N. C., Robinson, D., and Winchester, B. G.: Human liver $\alpha$-mannosidase activity. Clin. Chim. Acta, 55: 11 (1974).

38. Poenaru, L., and Dreyfus, J. C.: Electrophoretic heterogeneity of human $\alpha$-mannosidase. Biochim. Biophys. Acta, 303: 171 (1973).

39. Quie, P. G., White, J. G., Holmes, B., and Good, R. A.: In vitro bactericidal capacity of human polymorphonuclear luekocytes: Diminished activity in chronic granulomatous disease of childhood. J. Clin. Invest., 46: 668 (1967).

40. Robinson, D., Phillips, N. C., and Winchester, B.: Affinity chromatography of human liver $\alpha$-D-mannosidase. Fed. Eur. Biochem. Soc. Lett., 53: 110 (1975).
41. Sharp. H. L., and Desnick, R. J.: Sandhoff's disease: Diagnosis and evaluation by percutaneous liver biopsy. Gastroenterology, 60: 752 (1971).

42. Snaith, S. M.: Characterization of jack-bean $\alpha$-D-mannosidase as a zinc metalloenzyme. Biochem. J., 147: 83 (1975).

43. Snaith, S. M., Hay, A. G., and Levvy, G. A.: Relation between the $\alpha$-mannosidase activity and the zinc content of mammalian sex organs. J. Endocrinol, 50: 659 (1971).

44. Sung, J. H., Hayano, M., and Desnick, R. J.: Neuropathology of mannosidosis. J. Neuropathol. Exp. Neurol. (In press.)

45. Taylor, H. D., Thomas, G. H., Aylsworth, A., Stevenson, R. E., and Reynolds, C. W.: Mannosidosis: Deficiency of a specific $\alpha$-mannosidase component in cultured fibroblasts. Clin. Chim. Acta, 59: 93 (1975).

46. Tsay, G. C., Dawson, G., and Matalon, R.: Excretion of mannose-rich complex carbohydrates by a patient with $\alpha$-mannosidase deficiency (mannosidosis). J. Pediat.. 84: 865 (1974).

47. Tsay, G., Dawson, G., and Matalon, R.: Glycopeptide storage in skin fibroblasts cultured from a patient with $\alpha$-mannosidase deficiency. J. Clin. Invest., 56:711 (1975).

48. Woolen, J. W., and Walker, P. G.: The fluorimetric estimation of $\beta$-glucuronidase in blood plasma. Clin. Chim. Acta, 12: 659 (1965).

49. Research Products Incorporated, Elk Grove Village, Ill.

50. Reeve Angel, Clifton, N. J

51. Kalex Scientific, Manhasset, N. Y.

52. Informed consent for these studies was obtained from the parents of the homozygotes.

53. The authors wish to express their gratitude to Dr. J. G. Leroy for his expert clinical suggestions and fibroblast enzyme determinations and to Dr. L. Singer for the trace metal analyses. We also wish to thank Mr. Peter M. Anderson and Ms. Linda Walling for the electrophoretic studies, Mr. Mohanreddy Raman and Ms. Debra Seehausen for their skillful technical assistance, and Ms. Ardys Ferman for her expert clerical assistance.

54. Dr. R. J. Desnick is a recipient of National Institutes of Health Research Career Development Award KO4 AM 00042.

55. Dr. P. G. Quie is an American Legion Memorial Heart Research Professor.

56. These results were reported in part at the Twenty-Seventh Annual Meeting of the American Society of Human Genetics, Baltimore, Md., October 2-11, 1975, Amer. J. Hum. Genet., 27: 48A (1975).

57. This work was supported in part by a grant (1-273) from the National Foundation-March of Dimes; Grants AM 15174, AI 06931, and DE 01770 from the National Institutes of Health; Grant RR-400 from the General Clinical Research Center, Program of the Division of Research Resources, National Institutes of Health; and Grant 74-915 from the American Heart Association.

58. Requests for reprints should be addressed to: R. J. Desnick, Ph.D., M.D., Box 231 Mayo, University of Minnesota Hospitals, Minneapolis, Minn. 55455 (USA).

59. Accepted for publication June 8, 1976.
Airway resistance specific airway resistance thoracic gas volume

\title{
A Simplified Approach to the Measurement of Specific Airway Resistance
}

\author{
I. DAB AND F. ALEXANDER
}

Respiratory Physiology Department of the Astmacentrum, De Haan aan Zee, and Department of Pediatrics of the Free University of Brussels, Brussels, Belgium

\section{Extract}

A simple algebraic manipulation of known formulas leads to a direct expression for the specific airway resistance $\left(\mathbf{S R}_{\mathrm{aw}}\right)$ which precludes separate measurements of the airway resistance $\left(R_{a w}\right)$ and the thoracic gas volume (TGV). The equation is: $\mathbf{S R}_{\mathrm{aw}}=\operatorname{tg} \beta\left(\mathbf{P}_{\mathrm{Bar}}\right.$ $\left.-\mathbf{P}_{\mathrm{H}_{2} \mathrm{O}}\right) \mathbf{e}_{2}$, in which $\operatorname{tg} \beta$ stands for the relation between the plethysmographic box volume and pneumotachograph flow fluctuations; $\mathbf{P}_{\mathrm{Bar}}-\mathbf{P}_{\mathrm{H}_{2} \mathrm{O}}$ is the barometric pressure corrected for water vapor pressure at body temperature, and $e_{2}$ is a calibration for graphical units. Thanks to this new formula $\mathrm{SR}_{\mathrm{aw}}$ can now be easily measured with great precision and quickly calculated, even in the case of those children (Table 1) with whom this was not previously possible. No further cooperation is needed than breathing at a 
normal rate through mouthpiece into a whole-body plethysmograph. The intraindividual coefficient of variation $(\mathrm{CV})$ for $\mathrm{SR}_{\mathrm{aw}}$ is about $8 \%$ and never exceeds $15 \%$ (Table 1 ).

\section{Speculation}

Because of our proposed simplification of the measurement of $\mathrm{SR}_{\mathrm{aw}}$, the accumulation of data on bronchial obstruction and hence statistical analysis will be greatly facilitated in pediatrics. Further developments of this method should permit a comparison with previous studies in sedated children and answer the question of whether alteration in specific airway resistance is the consequence either of sedation or of some change associated with growth during the first 5 years life.

The respiratory function in children suffering from a chronic pulmonary disease should be studied repeatedly to enable an effective control of the evolution of their disease. Spirometric studies as advocated by Brough et al. (3) on children less than 8 years of age are not precise and depend on the cooperation of the subject. Plethysmographic measures which are much more precise were advocated by Radford (12) and Doershuk et al. (4, 5). However, such measurements require sedation for children younger than 5 years. For tests in series, this method therefore has little practical use in pediatrics. The importance of measuring $\mathrm{SR}_{\mathrm{aw}}$ (i.e., $\mathrm{R}_{\mathrm{aw}}$ times $\mathrm{TGV}$ at that volume at which $\mathrm{R}_{\mathrm{aw}}$ is measured) has been strongly emphasized by numerous authors (1, 2, 4, $5,8,11)$, most especially for children. It is a volume-corrected resistance which better describes an individual's pulmonary function than the use of either $R_{\mathrm{aw}}$ or TGV alone. In normal, nonsedated, mouth-breathing subjects, $\mathrm{SR}_{\mathrm{aw}}$ remains constant at any age (5), which is not the case of $T G V$ and $R_{a w}$. Any pathologic increase of $R_{a w}$ or TGV or both will immediately augment $S_{a w}$. Stimulated by these advantages, we decided to further investigate the matter. Our principal finding is that a simple algebraic manipulation of known formulas leads to a direct expression for $\mathrm{SR}_{\mathrm{aw}}$ which precludes separate measurements of $\mathrm{R}_{\mathrm{aw}}$ and $\mathrm{TGV}$.

\section{MATERIALS AND METHODS}

Twenty-two severely asthmatic children below the age of 5 , inpatients in an asthma institution (Asthmacentrum-Zeepreventorium, De Haan aan Zee, Belgium) were investigated in the first days after their admission. They were not especially trained for plethysmographic studies and only the first results were taken into account. Parents were informed of and agreed with the nonagressive investigation of their children. For every child who left the institution a copy of all the results was sent to the family doctor.

To measure $\mathrm{SR}_{\mathrm{aw}}$ we used a pressure-compensated volume displacement plethysmograph (Pulmorex (13)). The body box volume variations were measured with a Fleisch pneumotachograph no. 3. The plethysmograph was equipped on the inside with a Douglas bag of about 60 liters containing water heated by a thermostat to the desired temperature $\left(37^{\circ}\right.$ or more). The respiratory airflows were recorded at the mouth by a heated Fleisch pneumotachograph (no. 3) connected with a mouthpiece to the Douglas bag. The respiratory volumes were recorded by the integration of the flow signal of the same pneumotachograph. The child was thus able to breathe at a normal rate because BTPS conditions were met. Rebreathing did not exceed $1 \mathrm{~min}$, which is more than sufficient to record 5-10 respiratory cycles, so that hypercapnea and hypoxia were negligible. At any moment the respiration could be interrupted by a shutter in the mouthpiece to perform breathing movements against the closed shutter (Pflueger maneuver) and to record with an electronic manometer (13) the mouth pressure variations against the plethysmographic volume variations. All variables were simultaneously recorded on magnetic tape (14) and played back at one-fourth of the recording speed on an X-Y recorder (15). The pneumotachographs and the manometers were calibrated every day.
TGV was calculated with the help of the formula proposed by Matthys (9), a variant of the formula of Du Bois et al. (6)

$$
\mathrm{TGV}=\operatorname{tg} \alpha\left(\mathrm{P}_{\mathrm{Bar}}-\mathrm{P}_{\mathrm{H}_{2} \mathrm{O}}\right) \cdot \mathrm{e}_{1}
$$

In this equation, $\operatorname{tg} \alpha$ stands for the relation between the plethysmographic volume variation and the alveolar pressure variation at the exact moment of the Pflueger maneuver; $\mathbf{P}_{\mathrm{Bar}}$ stands for atmospheric pressure as read on the barometer; $\mathrm{P}_{\mathrm{H}_{2} \mathrm{O}}$ is the water vapor pressure at $37^{\circ} ; \mathrm{e}_{1}$ is a calibrating constant for the manometers to measure the alveolar pressure and the plethysmographic volume variations and is defined by the ratio of the number of milliliters of plethysmographic box variations per graphical unit on the $\mathrm{X}-\mathrm{Y}$ recorder to the pressure variations of the manometer at the mouth measured in $\mathrm{cm} \mathrm{H}_{2} \mathrm{O}$ per graphical unit on the $\mathrm{X}-\mathrm{Y}$ recorder $\left(e_{1}=\mathrm{ml} / \mathrm{mm}: \mathrm{cm} \mathrm{H}_{2} \mathrm{O} / \mathrm{mm}\right)$. $\mathrm{R}_{\mathrm{aw}}$ was also calculated with the help of the Matthys formula (9), which once more appears to be a variant of that of Du Bois et al. (7)

$$
\mathrm{R}_{\mathrm{aw}}=\operatorname{tg} \beta / \operatorname{tg} \alpha \cdot \mathrm{e}_{2} / \mathrm{e}_{1}
$$

In this equation, $\operatorname{tg} \beta$ represents the relation between the plethysmographic volume variation and the respiratory flow variation; $\mathrm{tg}$ $\alpha$ is the ratio of the plethysmographic volume variation on the alveolar pressure measured at the exact moment of the Pflueger maneuver. It is consequently the same relation as the one used for calculating TGV. $\mathrm{e}_{1}$ is the same calibrating constant as in the case of TGV and $e_{2}$ is. new calibrating constant defined by the ratio of the number of milliliters of plethysmographic box variations per graphical unit on the X-Y recorder to the flow variations measured in liters per sec per graphical unit on the $\mathrm{X}-\mathrm{Y}$ recorder $\left(\mathrm{e}_{2}=\right.$ $\mathrm{ml} / \mathrm{mm}: 1 / \mathrm{sec} /(\mathrm{mm})$ ). From Equation 1, we have

$$
\operatorname{tg} \alpha=\mathrm{TGV} /\left(\mathrm{P}_{\mathrm{Bar}}-\mathrm{P}_{\mathrm{H}_{2} \mathrm{O}}\right) \mathrm{e}_{1}
$$

Substituting $\mathrm{TGV} /\left(\mathrm{P}_{\mathrm{Bar}}-\mathrm{P}_{\mathrm{H}_{2} \mathrm{O}}\right) \mathrm{e}_{1}$ for $\operatorname{tg} \alpha$ in Equation 2 we obtain

$$
\mathbf{R}_{\mathbf{a w}}=\operatorname{tg} \beta / \mathrm{TGV}\left(\mathbf{P}_{\mathrm{Bar}}-\mathbf{P}_{\mathrm{H}_{2} \mathrm{O}}\right) \mathrm{e}_{2}
$$

However, by definition, we have $\mathrm{SR}_{\mathrm{aw}}=\mathrm{TGV} \times \mathrm{R}_{\mathrm{aw}}$, so that Equation 4 leads $\mathrm{SR}_{\mathrm{aw}}=\mathrm{TGV} \cdot \operatorname{tg} \beta / \mathrm{TGV}\left(\mathrm{P}_{\mathrm{Bar}}-\mathrm{P}_{\mathrm{H}_{2} \mathrm{O}}\right) \mathrm{e}_{2}$ to

$$
\mathrm{SR}_{\mathrm{aw}}=\operatorname{tg} \beta\left(\mathrm{P}_{\mathrm{Bar}}-\mathrm{P}_{\mathrm{H}_{2} \mathrm{O}}\right) \mathrm{e}_{2}
$$

We conclude that we are able to measure and calculate $\mathrm{SR}_{\mathrm{aw}}$ without knowing $\operatorname{tg} \alpha$, i.e., without having to make use of the Pflueger manoeuver.

\section{RESULTS}

In a preliminary study, with the help of Equations 1 and 2, we repeatedly measured $R_{a w}$ and $T G V$ in the first days after admission in 17 of our 22 children between 4 and 5 years of age (Table 1), and we calculated $\mathrm{SR}_{\mathrm{aw}}$ from the product of these two parameters. The mean values for TGV were calculated from three Pflueger manoeuvers. The mean values for $S R_{a w}$ and $R_{a w}$ were calculated from at least five flow-body volume curves for each child. Three children refused to get into the whole-body plethysmograph. Two children were frightened by the closing of the valve and did not perform the Pflueger maneuver. Many children, even some of those who had not been frightened, did execute the manoeuver, however, very badly. As a consequence these $R_{a w}$ and TGV values are not reproducible and are less precise. The $S R_{a w}$ values as calculated from Equation 5 are very reproducible (Table 1) and could be obtained in 19 nontrained children. The large range of values can be explained by the fact that the children studied are not representative of a normal sampling. The main point in this paper is to show that it is possible to measure $\mathrm{SR}_{\mathrm{aw}}$ quite easily and with great precision. The average time needed for measuring and calculating $\mathrm{SR}_{\mathrm{aw}}$, without both $\mathrm{TGV}$ and $\mathrm{R}_{\mathrm{aw}}$, was about $10 \mathrm{~min}: 2 \mathrm{~min}$ for instructions, 2-4 min for thermic equilibration of the plethysmograph after the subject had entered it, less than $1 \mathrm{~min}$ for registration of at least five flow-body 
Table 1. Comparison of $S R_{a w}$ as calculated from product $T G V \times R_{a w}$ and from formula $\operatorname{tg} \beta\left(P_{B a r}-P_{\mathrm{H}_{2} \mathrm{O}}\right) e_{2} ; R_{a \omega}$ is calculated from formula $\operatorname{tg} \beta / \operatorname{tg} \alpha \cdot e 2 / e_{1}{ }^{1}$

\begin{tabular}{|c|c|c|c|c|c|c|c|c|c|c|}
\hline Patient & Mean $\operatorname{tg} \alpha$ & Mean $\operatorname{tg} \beta$ & TGV & $\mathrm{SD}$ & $\mathrm{CV}, \%$ & $\mathrm{R}_{\mathrm{aw}}$ & $\mathrm{SR}_{\mathrm{aw}}$ & $\mathrm{SR}_{\mathrm{aw}}$ & $\mathrm{SD}$ & $\mathrm{CV}, \%$ \\
\hline 2 & 0.0354 & 0.1570 & 670 & 154 & 23 & 21.76 & 14.57 & 14.58 & 0.81 & 6 \\
\hline 4 & 0.0308 & 0.0742 & 590 & 99 & 17 & 11.68 & 6.89 & 6.89 & 0.58 & 8 \\
\hline 5 & 0.0296 & 0.1636 & 561 & 397 & 71 & 27.07 & 15.19 & 15.19 & 2.09 & 14 \\
\hline 6 & 0.0245 & 0.0925 & 465 & 370 & 80 & 18.48 & 8.59 & 8.59 & 0.64 & 7 \\
\hline $9^{2}$ & & 0.0750 & & & & & & 7.08 & 1.03 & 15 \\
\hline 10 & 0.0273 & 0.1216 & 524 & 86 & 16 & 21.77 & 11.41 & 11.42 & 1.08 & 9 \\
\hline 11 & 0.0298 & 0.1050 & 574 & 147 & 26 & 17.11 & 9.82 & 9.81 & 0.69 & 7 \\
\hline 12 & 0.0696 & 0.1246 & 1,320 & 21 & 2 & 8.74 & 11.54 & 11.53 & 0.46 & 4 \\
\hline 13 & 0.0210 & 0.0831 & 403 & 41 & 10 & 19.26 & 7.76 & 7.76 & 0.53 & 7 \\
\hline 14 & 0.0469 & 0.1063 & 914 & 197 & 22 & 11.11 & 10.15 & 10.15 & 0.21 & 2 \\
\hline 20 & 0.0259 & 0.1433 & 486 & 109 & 22 & 26.92 & 13.08 & 13.07 & 1.14 & 9 \\
\hline 21 & 0.0396 & 0.0927 & 742 & 313 & 42 & 11.41 & 8.47 & 8.46 & 0.77 & 9 \\
\hline 22 & 0.0471 & 0.0755 & 881 & 260 & 30 & 7.82 & 6.89 & 6.89 & 0.86 & 12 \\
\hline
\end{tabular}

${ }^{1} e_{1}$ and $e_{2}$ are calibrating factors for graphical units and depend on the scales that are used. $P_{\mathrm{Bar}}-\mathrm{P}_{\mathrm{H}_{2}} \mathrm{O}$ depends on the atmospheric pressure minus water vapor pressure at body temperature. There are small variations from day to day for this value. $S D=$ standard deviation. It is not calculated for $R_{a w}$. The error for $\mathrm{R}_{\mathrm{aw}}$ in this group of age depends chiefly on the error to TGV; mostly very high. $\mathrm{SR}_{\mathrm{aw}}=\mathrm{cm} \mathrm{H}_{2} \mathrm{O} \times \mathrm{sec}$. $\mathrm{R}_{\mathrm{aw}}=\mathrm{cm} \mathrm{H} \mathrm{H}_{2} \mathrm{O} / \mathrm{liter} / \mathrm{sec}$. TGV $=$ thoracic gas volume at mean end expiratory level in milliliters. (Should be converted to liters before calculating the product TGV $\times R_{a w}$ to work in the same units as for $R_{a w}$.)

${ }^{2}$ Pflueger maneuver impossible for patients 8 and 9.

${ }^{3}$ Patients 15,16 , and 17 refused to enter the box.

volume curves under BTPS conditions, and 1-2 min to put the values of these angles in a program-incorporated electronic calculator (16) and to have a print made of the mean, of the SD, and of the intraindividual $\mathrm{CV}$.

\section{DISCUSSION}

In our opinion it has been more than adequately demonstrated by Lloyd et al. (8), Payne et al. (11), and Doershuk et al. (5) that the essential criterion in the diagnosis of bronchial obstruction is $\mathrm{SR}_{\mathrm{aw}}$. To this end, the simplification which we arrived at through the derivation of Equation 5 is clearly of great advantage in that the necessity of two separate measurements is obviated. It may be useful here to recall the sources of error in the classic procedure of separate measurements of $R_{a w}$ and TGV. The Pflueger maneuver calibrates the plethysmographic volume variations in relation to the alveolar pressure variations. To know both $\mathrm{TGV}$ and $\mathrm{R}_{\mathrm{aw}}$, the alveolar pressure is essential. However, this maneuver is very difficult for most infants and many children and erroneous measurements will result when the subject closes his glottis, moves his jaws, or opens his mouth. This is the explanation for the large CV when calculating TGV (Table 1). Another possible source of error arises when the Pflueger maneuver is performed at some level other than the mean end expiratory level (TGV level) because $\operatorname{tg} \alpha$ increases with lung volume. This error can be corrected by using a magnetic tape, by subtracting a correction volume, and by converting the lung volume computed at the Pflueger maneuver level to the TGV level. On the other hand, for the calculation of $\mathbf{R}_{\mathbf{a w}}$ it is important to use $\operatorname{tg} \alpha$ at exactly the mean end expiratory level. As can be seen in Equation 2, and as was already experimentally stated in 1958 by Briscoe and Du Bois (2) and theoretically in 1968 by Nolte (10), during a respiratory cycle $\mathrm{R}_{\mathrm{aw}}$ will decrease with increasing lung volume (i.e., increasing $\operatorname{tg} \alpha$ ) to a minimum value at the end of inspiration, and increase with decreasing lung volume (i.e., decreasing $\operatorname{tg} \alpha$ ) to a maximum value at the end of expiration. $R_{a w}$, without further specification, is assumed to be the resistance at TGV level, and Equation 2 is thus valid only for that level. In the authors' experience, however, it seems that the Pflueger maneuver is most easily performed with minimal error in small children after the onset of expiration. $\mathrm{SR}_{\mathrm{aw}}$ calculated by the usual formula $\left(R_{a w} \times T G V\right)$ is the product of lung volume and resistance at the Pflueger maneuver level (at that volume) and hence is the product of $T G V$ and $R_{a w}$ corrected to what it would be at the mean end expiratory level (Equation 4). In the event that the correction is made neither on the lung volume nor on the resistance, it is evident that the same $\mathrm{SR}_{\mathrm{aw}}$ will be obtained. The point of the present paper, however, is that these problems inherent to the Pflueger maneuver are avoided by our Equation 5. In Table I we have presented in parallel columns $S_{2}$ as measured by the usual technique, a multiplication of the two factors $T G V$ and $R_{a w}$, and $S_{a w}$ as obtained in a single measurement according to Equation 5. Apart from differences in the last digit, presumably because of the multiplication of rounding errors in the usual method, it is seen that agreement is very good. Indeed, because $\mathrm{SR}_{\mathrm{aw}}$ is independent of the Pflueger manoeuver, the $\mathrm{CV}$ will be relatively small (Table 1). Moreover, $\mathrm{SR}_{\mathrm{aw}}$ can now be measured in those two children (Table 1) with whom this was not previously possible.

Thanks to the new formula $\mathrm{SR}_{\mathrm{aw}}$ can be easily measured with great precision, and quickly calculated, for all children who are willing to get into a whole-body plethysmograph. All children who initially refused to enter in the box later agreed to it when they felt more at ease. However, only the first results are reproduced here to demonstrate that time-consuming instructional procedures (3) are superfluous to obtain a reliable measurement in the majority of cases. 


\section{SUMMARY}

A new method of calculating the specific airway resistance in a whole-body plethysmograph is proposed. The only data needed are the simultaneous pneumotachograph flow and plethysmograph box volume fluctuations, without the knowledge of alveolar pressure.

This will often be the only objective datum that can be obtained with a whole-body plethysmograph in nonsedated children under the age of 6 or 7 years.

\section{REFERENCES AND NOTES}

1. Bouhuys, A.: Breathing. In: Physiology, Environment and Lung Disease, p. 160 (Grune \& Stratton, New York, 1974).

2. Briscoe, W. A., and Du Bois, A. B.: The relationship between airway resistance, airway conductance and lung volume in subjects of different age and body size. J. Clin. Invest., 37: 1279, (1958).

3. Brough, F. K. Du Wayne Schmidt, C., Dickman, M., and Jackson, B.: Effect of two instructional procedures on the performance of the spirometry test in children five through seven years of age. Amer. Rev. Resp. Dis., 106: 604, (1972).

4. Doershuk, C. F., Downs, T. D., Matthews, L. W., and Lough, M. D.: A method for ventilatory measurements in subjects 1 month-5 years of age: Normal results and observations in disease. Pediat. Res., 4: 165. (1970).

5. Doershuk, C. F., Fisher, B. J., and Matthews, L. W.:Specific airway resistance from perinatal period into adulthood. Amer. Rev. Resp. Dis., 109: 452 (1974).

6. Du Bois, A. B., Botelho, S. Y., Bedell, G. N., Marshall, R., and Comroe, J.
H., Jr.: A rapid plethysmographic method for measuring thoracic gas volume: A comparison with a nitrogen washout method for measuring functional residual capacity in normal subjects. J. Clin. Invest., 35: 322 (1956).

7. Du Bois, A. B., Botelho, S. Y., and Comroe, J. H., Jr.: A new method for measuring airway resistance in man using a body-plethysmograph: Values in normal subjects and in patients with respiratory disease. J. Clin. Invest., 35: 327. (1956).

8. Lloyd, T. C., Jr., and Wright, G. W.: Evaluation of methods used in detecting changes of airway resistance in man. Amer. Rev. Resp. Dis., 87: 529, (1963).

9. Matthys, H.: Lungenfunktionsdiagnostik mittels Ganzkörperplethysmographie, pp. 2-7 (F. K. Schattauer Verlag, Stuttgart, 1972).

10. Nolte, D., Reif, E., and Ulmer, W. T.: Die Ganzkörperplethysmographie. Respiration, 25: 14 (1968).

11. Payne, C. B., Jr., Chester, E. H., and Hsi, B. P.: Airway responsiveness in chronic obstructive pulmonary disease. Amer. J. Med., 42: 554 (1965).

12. Radford, M.: Measurement of airway resistance and thoracic gas volume in infancy. Arch. Dis. Childhood, 49: 611 (1974).

13. Fenyves \& Gut, Basel, Switzerland.

14. Sony three-head stereo recorder, Sony Instrument Co., Tokyo, Japan.

15. Hewlett-Packard 7041A. Hewlett-Packard, Avondale, Pa.

16. Compucorp 325 Scientist, Compucorp Corp., Los Angeles, Calif

17. The writers thank Mrs. Monballiu for the careful assistance with the respiratory function tests.

18. These data were presented at the VIllth Interasma-Congress, Vlissingen-De Haan (Netherlands and Belgium), October 1975.

19. This research was supported by Grant no. 3.0015.75, National Fund for Medical and Scientific Research in Belgium.

20. Requests for reprints should be addressed to: I Dab, M.D. Universitair Ziekenhuis St. Pieter. Dienst Kindergeneeskunde, Hoogstraat 320, 1000 Brussels (Belgium).

21. Accepted for publication June 11, 1976.

Pediat. Res. 10: 999-1000 (1976)

\title{
Letter to the Editor
}

\author{
Q. T. SMITH, ${ }^{7}$ M. J. HAMILTON, AND B. L. SHAPIRO
}

Division of Oral Biology, School of Dentistry, University of Minnesota, Minneapolis, Minnesota, USA

Research on cystic fibrosis (CF), early detection of CF, and genetic counseling relative to $C F$ would all benefit greatly from availability of a simple technique for detection of CF heterozygotes and homozygotes. Consequently, various investigators have devoted much effort in attempts to identify differences in body fluids, especially serum, from CF heterozygotes and homozygotes. The objective of several of these studies has been detection of an abnormal component, for example the "CF factor," which could be used for identification of affected individuals and carriers and which would be useful for the laboratory study of the pathophysiology of CF. Thus the recent reports of serum protein differences in CF (5) and the claim recently published in Pediatric Research (4) to have "developed a standardized biophysical assay for the rapid detection of individuals homozygous and heterozygous for $\mathrm{C} / \mathrm{F}$ " were particularly significant. According to these papers a protein band with an isoelectric point of 8.4-8.5 was present following thin layer isoelectric focusing in polyacrylamide gel from serum of CF homozygotes and heterozygotes but not from control subjects. This protein was reported to be dissociated from IgG by 4 $M$ urea and to have a molecular weight between 1,000 and 10,000. Because of our experience with isoelectric focusing and polyacryl- amide gel electrophoresis and our interest in CF we have attempted to confirm the presence of the $\mathrm{pH} 8.4-8.5$ isoelectric point protein in CF homozygotes. The results of these efforts are summarized below.

We examined serum proteins from $18 \mathrm{CF}$ subjects and 14 control individuals according to the first procedure described by Wilson, Jahn, and Fonseca in 1973 (5) and as later modified and published in Pediatric Research in 1975 by Wilson, Fudenberg, and Jahn (4). The only difference in our technique of which we are aware is use of an LKB Multiphor electrophoresis apparatus rather than the equipment described by Williamson (3). This difference should not be significant since a linear and reproducible $\mathrm{pH}$ gradient was obtained with our apparatus and since large amounts of protein were present at $\mathrm{pH} 8.0-9.0$ in the gels. We were unable to detect any consistent differences between the stained serum protein patterns of the CF and the control subjects. Figure 1 gives an example of the isoelectric focusing patterns in polyacrylamide gel of $\mathrm{CF}$ and control serum proteins and of the isoelectric focusing $\mathrm{pH}$ gradients obtained in our laboratory. These patterns show greater resolution of proteins than those previously published $(\dot{4}$, $5)$, but, in contrast, no consistent differences between CF and 